This paper is originally published with the following reference :

Nanoscale. , 6 : 9264 - 9272 (2014). DOI: 10.1039/c4nr02239d

\title{
Multimodal Mn-doped I-III-VI quantum dots for near infrared fluorescence and magnetic resonance imaging: from synthesis to in vivo application
} Gary Sitbon, ${ }^{a, b, c}$ Sophie Bouccara, ${ }^{a, b, c}$ Mariana Tasso,${ }^{a, b, c}$ Aurélie Francois, ${ }^{d}$ Lina Bezdetnaya, ${ }^{d}$
Frédéric Marchal,,${ }^{d}$ Marine Beaumont ${ }^{e}$ and Thomas Pons $s, b, c, *$

a LPEM, PSL Research University, ESPCI-ParisTech, 10 rue Vauquelin, F-75231 Paris

Cedex 5, France

b CNRS, UMR 8213, F-75005 Paris, France

c Sorbonne Universités, UPMC Univ Paris 06, F-75005 Paris, France

d Centre de Recherche en Automatique de Nancy (CRAN), ICL, Université de Lorraine, UMR 7039, Campus Sciences, BP 70239, 54506 Vandoeuvre-lès-Nancy Cedex, France

e CIC-IT de Nancy, CHU de Nancy, Hôpitaux de Brabois, rue du Morvan, 54511

Vandoeuvre-lès-Nancy, France

*thomas.pons@espci.fr

\begin{abstract}
The development of sensitive multimodal contrast agents is a key issue to provide better global, multi-scale images for diagnostic or therapeutic purposes. Here we present the synthesis of $\mathrm{Zn}-\mathrm{Cu}-\mathrm{In}-(\mathrm{S}, \mathrm{Se}) / \mathrm{Zn}_{1-\mathrm{x}} \mathrm{Mn}_{\mathrm{x}} \mathrm{S}$ core/shell quantum dots (QDs) that can be used as markers for both near-infrared fluorescence imaging and magnetic resonance imaging (MRI). We first present the synthesis of $\mathrm{Zn}-\mathrm{Cu}-\mathrm{In}$-(S,Se) cores coated with a thick $\mathrm{ZnS}$ shell doped with various proportions of Mn. Their emission wavelengths can be tuned over the NIR optical window suitable for deep tissue imaging. The incorporation of manganese ions (up to a few thousand ions per QD) confers them a paramagnetic character, as demonstrated by structural analysis and electron paramagnetic resonance spectroscopy. These QDs maintain their optical properties after transfer to water using ligand exchange. They exhibit T1relaxivities up to $1400 \mathrm{mM}^{-1}[\mathrm{QD}] . \mathrm{s}^{-1}$ at $7 \mathrm{~T}$ and $300 \mathrm{~K}$. We finally show that these QDs are suitable multimodal in vivo probes and demonstrate MRI and NIR fluorescence detection of regional lymph nodes in mice.
\end{abstract}




\section{INTRODUCTION}

Noninvasive molecular imaging is being increasingly used both as a scientific tool to study biological processes in living organisms and as a diagnostic tool to provide clinicians with an otherwise inaccessible image of a specific marker distribution. ${ }^{1-3}$ Each imaging modality presents complementary advantages in terms of sensitivity, spatial resolution, imaging depth and ease of use. ${ }^{4,5}$

Near infrared fluorescence imaging (NIRFI), in particular, is attracting increasing attention due to its high sensitivity, low cost, non-invasiveness and easy implementation. It is however limited to near surface tissues, since its imaging depth does not exceed a few centimeters. Its spatial resolution varies from the micrometer scale using microscopy on cell samples to centimeters in thick tissues, due to light diffusion. Magnetic resonance imaging (MRI), on the other hand, provides whole body images with a homogeneous millimeter-resolution, albeit with a lower sensitivity. Nanotechnology offers the potential to design probes that offer contrast in both imaging modalities and combine the best of each, therefore providing a more comprehensive picture of the biological markers of interest. In particular, fluorescent semiconductor quantum dots (QDs) represent an attractive platform to integrate different contrast agents.

During the past decade, visible emitting QDs have increasingly been used for cellular imaging due to their unique optical properties such as their high brightness, photo-stability and multiplexing capabilities. They have for example enabled long term tracking of single molecules or simultaneous labeling of many different biomolecular targets. ${ }^{6,7}$ QDs are also being increasingly used for in vivo imaging to improve detection sensitivities. ${ }^{8,9}$ For in vivo applications, however, QDs should emit in the NIR range, typically between $700 \mathrm{~nm}$ and 1000 $\mathrm{nm}$, in order to minimize light absorption and diffusion and therefore maximize imaging depth. ${ }^{10}$ While no signs of acute toxicity have been observed after the injection of large doses of Cd-based QDs, ${ }^{11}$ safer, heavy-metal free QDs have been developed in order to minimize toxicity. Recently developed silicon-based QDs, ${ }^{12,13}$ as well as QDs based on I-III-VI 2 materials such as $\mathrm{CuInS}_{2}$ or $\mathrm{CuInSe}_{2}{ }^{14-17}$ provide attractive fluorescent probes for biomedical applications due to their low toxicity and high detection sensitivities.

Several strategies have been used to bring together fluorescence and MR contrast into one nanoprobe using I-III-VI QDs. For example, Hsu et al. incorporated $\mathrm{CuInS}_{2} / \mathrm{ZnS}$ QDs and superparamagnetic iron oxide nanoparticles in silica beads. ${ }^{18}$ However, the resulting size is much larger than the original nanoparticles, which may hinder access to confined spaces. In order to obtain more compact nanoprobes, Cheng et al. have encapsulated $\mathrm{CuInS}_{2} / \mathrm{ZnS}$ QDs in an amphiphilic polymer, to which they coupled $\mathrm{Gd}^{3+}$-chelates. ${ }^{19}$ In addition to the relatively low number of Gd conjugated per QD, leading to a small relaxivity per QD, this strategy may suffer from the weak non-covalent link between the QD and the paramagnetic ion. Indeed, the QD organic surface chemistry may easily detach with time from the QD surface due to its interaction with the complex in vivo environment, as has been shown for example for micelle encapsulated QDs. ${ }^{20}$ Even relatively strong dithiol-containing ligands have been shown to exhibit a fast desorption rate from the QD surface, on the order of $1 \mathrm{~h}^{-1} .^{21}$ The dissociation 
between the fluorescent QDs and the magnetic species linked to the surface ligands therefore represents a strong limitation to the use of this type of multimodal probe for in vivo imaging.

We have therefore chosen to directly incorporate the paramagnetic ion into the QD inorganic shell to ensure that at all times the fluorescent and magnetic species remain colocalized. Doping of QDs with $\mathrm{Mn}^{2+}$ ions has been reported earlier in II-VI QDs. ${ }^{22}$ Wang et al. demonstrated the use of Mn-doped CdSe/ZnS QDs for in vitro fluorescence and MR imaging of macrophages. ${ }^{23}$ More recently, several groups reported the synthesis of $\mathrm{Mn}$-doped $\mathrm{CuInS}_{2}$ or $\mathrm{AgInS}_{2}$ QDs. ${ }^{24-26}$ However, none of these QDs emit in the NIR. In addition, they were only able to incorporate a small number of Mn per QD, leading to a low MR sensitivity. These two limitations precluded their use for in vivo imaging. Here we report the synthesis and characterization of $\mathrm{Zn}-\mathrm{Cu}-\mathrm{In}-(\mathrm{S}, \mathrm{Se}) / \mathrm{Zn}_{1-\mathrm{x}} \mathrm{Mn}_{\mathrm{x}} \mathrm{S}$ QDs designed for in vivo imaging: the emission of these QDs is tunable in the NIR range for optimal fluorescence imaging and they contain up to $3000 \mathrm{Mn}$ atoms. This very high Mn loading leads to relaxivities in the $\mu \mathrm{M}(\mathrm{QD})^{-}$ ${ }^{1} . \mathrm{s}^{-1}$ range and allows QD-based multimodal in vivo imaging. As an illustration, we demonstrate in vivo MRI and fluorescence detection of regional lymph nodes in mice.

\section{MATERIALS AND METHODS}

\section{Chemicals.}

All chemicals were purchased from Sigma-Aldrich and used as received without further purification. Zinc ethyl xanthogenate $\left(\mathrm{Zn}(\mathrm{EtX})_{2}\right)$ and zinc oleate $\left(\mathrm{Zn}(\mathrm{OA})_{2}\right)$ were prepared from zinc nitrate, potassium ethylxanthogenate and sodium oleate according to previously reported methods ${ }^{16}$. HeLa cells were obtained from ATCC and cultured using supplemented DMEM medium (DMEM, high glucose, GlutaMAX, pyruvate, 10 vol\% FBS, 1 vol\% penicillin-streptomycin) from Gibco.

\section{Synthetic procedures}

Synthesis of $\mathbf{Z n}-\mathrm{Cu}$-In-S cores. In a typical synthesis of $\mathrm{Zn}-\mathrm{Cu}-\mathrm{In}-\mathrm{S}$ cores, $1 \mathrm{mmol}$ of copper (I) iodide $(190 \mathrm{mg}), 1 \mathrm{mmol}$ of indium acetate $(291 \mathrm{mg})$ and $0.1 \mathrm{mmol}$ of zinc acetate $\left(\mathrm{Zn}(\mathrm{OAc})_{2}, 18 \mathrm{mg}\right)$ were introduced in a three-neck flask with $5 \mathrm{ml}$ of dodecanethiol (DDT) and degassed under vacuum at $40^{\circ} \mathrm{C}$ for $30 \mathrm{~min}$. The yellow turbid suspension was then placed under argon flow and heated to $120^{\circ} \mathrm{C}$ for $10 \mathrm{~min}$. The resulting clear yellow solution was subsequently further heated to $220^{\circ} \mathrm{C}$. After approximately 15 minutes, the mixture was quickly cooled to room temperature. The obtained $780 \mathrm{~nm}$-emitting $\mathrm{Zn}-\mathrm{Cu}-\mathrm{In}-\mathrm{S}$ cores were then collected by precipitation with ethanol $(\mathrm{EtOH})$ and washed three times by successive redispersion and precipitation in hexane/EtOH. The final precipitate was redispersed in $10 \mathrm{ml}$ of hexane.

Synthesis of $\mathbf{Z n}-\mathrm{Cu}-\mathrm{In}-\mathrm{Se}$ cores. In a typical synthesis of $\mathrm{Zn}$-Cu-In-Se cores, $1 \mathrm{mmol}$ of $\mathrm{CuCl}(99 \mathrm{mg}), 1 \mathrm{mmol}$ of $\mathrm{InCl}_{3}(221 \mathrm{mg}), 2 \mathrm{mmol}$ of $\mathrm{Zn}(\mathrm{OAc})_{2}(367 \mathrm{mg})$ and $2 \mathrm{mmol}$ of selenourea $(246 \mathrm{mg}$ ) were introduced in a $100 \mathrm{ml}$ three neck flask with $10 \mathrm{ml}$ of trioctylphosphine and $25 \mathrm{ml}$ of octadecene (ODE). After sonicating the suspension for a few minutes, we added $5 \mathrm{ml}$ of DDT and $10 \mathrm{ml}$ of oleylamine (OAm). The resulting pink solution 
is degassed for 30 minutes at $40^{\circ} \mathrm{C}$. The solution is then heated at $230^{\circ} \mathrm{C}$ and turned from pink to black. After 80 minutes of heating, $800 \mathrm{~nm}$-emitting $\mathrm{Zn}-\mathrm{Cu}$-In-Se cores were obtained and purified as described above. The final black precipitate was redispersed in $10 \mathrm{ml}$ of hexane.

Growth of a $\mathrm{Mn}_{\mathrm{x}} \mathrm{Zn}_{1-\mathrm{x}} \mathrm{S}$ shell. We used a dropwise injection for the growth of a $\mathrm{Mn}_{\mathrm{x}} \mathrm{Zn}_{1-\mathrm{x}} \mathrm{S}$ shell on $\mathrm{Zn}-\mathrm{Cu}-\mathrm{In}-\mathrm{E}(\mathrm{E}=\mathrm{S}$ or $\mathrm{Se}$ ) cores. The first solution (solution 1) was composed of 2.5 mmol of $\mathrm{Zn}(\mathrm{EtX})_{2}(768 \mathrm{mg}), 3 \mathrm{ml}$ of OAm and $7 \mathrm{ml}$ of ODE. It resulted in a white turbid solution. The second solution (solution 2) is prepared in a $100 \mathrm{ml}$ three neck flask. We introduced 2,5-x mmol de $\mathrm{Zn}(\mathrm{OA})_{2}, 2 \mathrm{ml}$ OLA and $8 \mathrm{ml}$ ODE. The solution was degassed under vacuum at $120^{\circ} \mathrm{C}$ for 10 minutes. After the solution was cooled to room temperature, we introduced $\mathrm{x}$ mmol of manganese (II) acetate and the solution was then degassed again under vacuum at $120^{\circ} \mathrm{C}$ for 10 minutes. The orange solution is kept under argon prior to the injection.

In a $100 \mathrm{ml}$ three neck flask, we mixed $1 \mathrm{ml}$ of core QD solution prepared as mentioned above and $10 \mathrm{ml}$ of $\mathrm{ODE}$. The solution was degassed under vacuum at $50^{\circ} \mathrm{C}$ for 40 minutes and then heated at $200^{\circ} \mathrm{C}$ under argon. Solution 1 and solution 2 were then injected simultaneously in 2 hours. After cooling at room temperature, QDs were purified as described above and redispersed in $10 \mathrm{ml}$ of hexane.

Water solubilization. QDs can be transferred in water by cap exchange with polyethylene glycol (PEG) modified-dihydrolipoic acids (DHLA-PEG) prepared according to a literature method with commercially available Jeffamine M-1000 polyetheramine (Huntsman). ${ }^{27}$ A twostep surface modification was first performed to facilitate the subsequent water solubilisation. For that, $1 \mathrm{ml}$ of QD solution was precipitated with ethanol and resuspended in chloroform. They were left overnight at $60^{\circ} \mathrm{C}$ in the presence of $200 \mu \mathrm{L}$ OAm. QDs were then precipitated with acetone and redispersed in chloroform. We then added $100 \mathrm{mg} \mathrm{Zn}(\mathrm{OA})_{2}$ and the solution was heated to $60^{\circ} \mathrm{C}$ for 2 hours. After precipitation with acetone to remove excess ligands and redispersion in chloroform, cap exchange and purification were done as reported before. ${ }^{15}$

\section{Characterization}

Optical characterization Absorption spectra were performed using a UV-Visible Varian Cary-5E spectrometer. Photoluminescence excitation spectra were performed using a Horiba Jobin Yvon Fluoromax-3 spectrofluorometer. Photoluminescence spectra and fluorescence lifetime measurements were performed using an Edinburgh Instruments FSP920 spectrofluorometer. The excitation source was either an Edinburgh Instruments EPL375 laser diode with an emission wavelength at $376 \mathrm{~nm}$ or a xenon $450 \mathrm{~W}$ arc lamp. The detector used for the experiments was a Hamamatsu R2658P side window photomultiplier. Photoluminescence quantum yields (QY) were measured using zinc phtalocyanine as reference, according to a previously reported method. ${ }^{15}$

Structural characterization TEM/HRTEM images were acquired using a JEOL 2010 TEM equipped with a Gatan camera. XRD powder diffraction patterns were acquired using a Philips X'Pert diffractometer with a $\mathrm{Cu} \mathrm{K} \mathrm{K}_{\alpha}$ source. We determined the size of crystalline domain, $d$, using Scherrer's law: 


$$
d=\frac{K \lambda}{F W H M \cos \theta}
$$

where $K$ is a dimensionless shape factor (a typical value of 0.9 for spherical objects was used as a first approximation), $\beta$ is the FWHM of the peak (in radians) and $\theta$ is the Bragg angle of the corresponding peak.

EPR measurements were performed using a Bruker EMX spectrometer operating at $\mathrm{X}$ band frequency $(9.7 \mathrm{GHz})$.

Elemental analysis was performed by energy-dispersive X-ray spectroscopy (EDX) on a Hitachi S-3600N scanning electron microscope operated at $15 \mathrm{keV}$. ICP-AES analyses were performed by Repsem analytical platform in Strasbourg. Samples are prepared by dissolving dried QDs with nitric acid.

Dynamic light scattering (DLS) was carried out on a CGS-3 goniometer system equipped with HeNe laser illumination at $633 \mathrm{~nm}$ and an ALV/LSE-5003 correlator (Malvern). Purified QD solutions are filtered $(0.2 \mu \mathrm{m})$ and measured at five different angles between $45^{\circ}$ and $120^{\circ}$.

Zeta potentials were measured in triplicate in water using a Malvern Zetasizer.

Manganese ions leaching Manganese leaching was measured by colorimetry using 3,3',5,5'tetramethylbenzidine (TMB) as described by Bosch-Serrat. ${ }^{28}$ Purified hydrophilic quantum dots were dispersed in cell culture medium (optiMEM reduced serum, no phenol red medium, Gibco) at a concentration of $1 \mu \mathrm{M}$ and left at $37^{\circ} \mathrm{C}$. After different incubation times, free manganese ions are separated from QDs by ultrafiltration (100 kDa cutoff), quantified using TMB absorbance at $450 \mathrm{~nm}$ and standard calibration solutions.

Relaxivity characterization Spin-lattice relaxivities $\left(r_{1}\right)$ were measured at $7 \mathrm{~T}$ and room temperature using a Bruker asx 300MHz NMR spectrometer. A solution containing QD was introduced in a $200 \mu 1$ Teflon sample holder and put in the spectrometer. We then used an inversion recovery protocol with various time delays, $\tau$, between the $180^{\circ}$-inversion pulse and the $90^{\circ}$-reading pulse. The NMR signal, $M$, for a given time delay $\tau$, is given by

$$
M(\tau)=M_{0}\left(1-\exp \left(-\frac{\tau}{T_{1}}\right)\right)
$$

where $M_{0}$ is the NMR signal before inversion. $\mathrm{T}_{1}$ is obtained from the above equation (see Figure S6a in ESI). Relaxation measurements were performed at different QD concentrations to obtain the relaxivity of each QD sample (Figure S6b).

Cell viability assay To assess the cytotoxicity of our probes, we performed a colorimetric MTT assay on HeLa cells. The assay is based upon the reduction of yellow 3-(4,5dimethylthiazol-2-yl)-2,5-diphenyltetrazolium bromide to its purple formazan by viable cells. HeLa cells were seeded on a 96-well plate at a density of 10000 cells per well. After overnight incubation at $37^{\circ} \mathrm{C}$ and $5 \% \mathrm{CO}_{2}$, culture medium was removed and cells were rinsed with phosphate buffer saline (PBS) solution. Then, $100 \mu 1$ of culture medium containing QDs at various concentrations were added. These QD solutions were pre-filtered $(0.2 \mathrm{um})$ for 
sterilization. After 24 hours of incubation at $37^{\circ} \mathrm{C}$ and $5 \% \mathrm{CO}_{2}$, medium was removed and cells were rinsed with PBS. We then added $100 \mu \mathrm{l}$ of culture medium and $20 \mu \mathrm{l}$ of a solution of MTT in water $(5 \mathrm{mg} / \mathrm{ml})$. After 2 hours incubation, culture medium was removed and cells were rinsed with PBS. $150 \mu \mathrm{l}$ of a $10 \%$ vol Triton X-100 in isopropanol was added to cells. After 30 minutes incubation, absorbance at $550 \mathrm{~nm}$ was measured on an absorbance microplate reader. Three replicates for each condition were considered, as well as i) a blank control with only cell medium, and ii) a control with the highest evaluated nanoparticle concentration in cell medium. This latter control intended to assess eventual (and parasitic) MTT reagent conversion induced by QD nanoparticles. ${ }^{29,30}$ In our assays, such an effect was not observed: the absorbance of the only-QDs control was similar to the one of the blank with only medium. Furthermore, all reported absorbance values are increments relative to the absorbance of the blank.

\section{In vivo experiments}

Animals and QD administration All animal experiments were conducted in agreement with the Principles of Laboratory Animal Care (National Institutes of Health publication no. 86-23, revised 1985) and approved by the regional ethics committee. Female C57/BL6 mice (Janvier, Le Genest-Isle, France) were used in this study and maintained under specific pathogen-free conditions. $300 \mu \mathrm{l}$ of a $40 \mu \mathrm{M}$ stock solution of $\mathrm{CuInSe}{ }_{2} / \mathrm{Zn}_{0.8} \mathrm{Mn}_{0.2} \mathrm{~S}$ QDs was ultrafiltered and the pellet was dissolved in $60 \mu \mathrm{l}$ of PBS. All experiments were performed under anesthetic using intraperitoneal injection of $0.01 \mathrm{ml} / \mathrm{g}$ of body weight of a solution containing $9 \mathrm{mg} / \mathrm{ml}$ of ketamine (Ketalar®, Panpharma, Fougères, France) and $0.9 \mathrm{mg} / \mathrm{ml}$ of xylazine (Rompun ${ }^{\circledR}$, Bayer Pharma, Puteaux, France). Female C57/BL6 mice (Janvier, France) were injected subcutaneously in the distal part of the left anterior paw with $20 \mu 1$ of QD solution. After product delivery, the left paw was kneaded to improve product migration. Immediately after injection, animals were placed in the MR scanner, in the same position as before QD injection.

Magnetic Resonance Imaging MRI was performed on a 3T MR scanner (SIGNA HDxt, General Electric, Milwaukee, WI) using a four channel volume coil for reception (RAPID Biomedical, Rimpar, Germany). T1-weighted images were acquired using a fast spin-echo sequence with the following parameters: TE/TR $=12 / 500 \mathrm{~ms}$; acquisition matrix $=480 \times 320$; field of view $=120 \mathrm{~mm}^{2}$ and 171 -mm-thick slices. Acquisitions were performed pre and post (20min) QD injection.

Near-Infrared Fluorescence Imaging In vivo optical imaging of QDs was performed using a Fluobeam ${ }^{\circledR}$ (Fluoptics, Grenoble, France) NIR imaging system. A 750-nm longpass emission filter is used. The regions of interest (ROIs) were depilated using a commercial hair removal cream before imaging. The CCD camera shows the specificity to adjust the fluorescence signal on the pixel which presents the strongest fluorescence intensity. Thus, the injection point of QDs was hidden if necessary, allowing thereby a better ROI visualization. In vivo fluorescence of axillary lymph nodes and lateral thoracic was acquired after MRI experiments, about $1 \mathrm{~h}$ after QD administration. 


\section{RESULTS AND DISCUSSION}

\section{Growth of thick zinc sulfide shell on $\mathrm{Zn}-\mathrm{Cu}-\mathrm{In}-\mathrm{S}$ cores}

We first synthesized $\mathrm{Zn}-\mathrm{Cu}-\mathrm{In}-\mathrm{S}$ core QDs using a protocol adapted from Li et al. ${ }^{14}$. We added a small amount of zinc precursors to the core synthesis as this improved the core photoluminescence quantum yield (PL QY), ${ }^{15}$ without restricting the tunability of the emission in the NIR region due to the increase of the bang gap. The Zn content was indeed typically limited to $25 \%$ compared to the $\mathrm{Cu}$ content, as estimated from EDS, and the Cu/In ratio was close to one. The obtained $\mathrm{Zn}-\mathrm{Cu}-\mathrm{In}-\mathrm{S}$ cores typically emitted at $780 \mathrm{~nm}$, with a FWHM of $100 \mathrm{~nm}$, and a PL QY of $30 \%$. While the size of these cores was difficult to estimate from TEM images due to low contrast, X-ray diffractograms were consistent with a core size of about $3 \mathrm{~nm}$ using Scherrer's law (see Materials and Methods section).

Our objective was then to grow a thick $\mathrm{ZnS}$ shell to be able to incorporate at later stages a maximal number of paramagnetic $\mathrm{Mn}^{2+}$ ions in the shell. Layer by layer deposition of $\mathrm{ZnS}$ on quantum dots following a SILAR protocol ${ }^{31}$ required elevated temperatures $\left(>240{ }^{\circ} \mathrm{C}\right)$ to activate low reactivity precursors (zinc oleate and sulfur dissolved in octadecene). At these temperatures however, QD cores were rapidly etched, while lower temperatures resulted in an absence of growth. Previously described protocols were able to yield thin $(1 \mathrm{~nm}) \mathrm{ZnS}$ shell around $\mathrm{Zn}-\mathrm{Cu}-\mathrm{In}-\mathrm{S}$ cores using dropwise injection of more reactive zinc ethylxanthate or dithiocarbamate precursors. ${ }^{14,15}$ However the injection of additional precursors resulted in secondary nucleation of $\mathrm{ZnS}$ nanocrystals without increasing the shell thickness. We found that adjusting (see Materials and Methods for details) the amount of oleylamine and the injection speed helped growing thicker monocrystalline shells, in the range of 2-3 nm, corresponding to about $10 \mathrm{ZnS}$ monolayers, as shown in Figure 1a by TEM $(8 \pm 2 \mathrm{~nm}$ in diameter) and XRD (7 $\pm 1 \mathrm{~nm})$.

The resulting QDs retained their emission properties in the near infrared (Figure 1b), with a small blue shift which could be attributed to the incorporation of $\mathrm{Zn}$ in the core due to cation exchange and/or Zn interdiffusion. ${ }^{15,32}$ Photoluminescence excitation (PLE) spectrum showed a sharp rise below $350 \mathrm{~nm}$, corresponding to the contribution of $\mathrm{ZnS}$. This confirms the growth of a thick ZnS shell on the fluorescent QD cores. Comparison of PLE and absorption spectra indicates a limited secondary nucleation (typically less than 10\%). Fluorescence decays showed a long lifetime component around 200 ns (see Figure S1 in ESI), which is typical for these I-III-VI QDs. ${ }^{14,33}$

\section{Incorporation of manganese in the shell.}

To incorporate manganese in the $\mathrm{ZnS}$ shell, we simply replaced zinc oleate with manganese acetate in the injection solution using different ratios of $\mathrm{Mn}$ to $\mathrm{Zn}$. To avoid oxidation of manganese, the solution was carefully degassed under vacuum before adding the manganese precursor, as was previously described by Yang et al. ${ }^{34}$ We thus synthesized samples with 1 , 2, 5, 10, 20 and $30 \%$ of manganese precursor in the injection of solution. 
Incorporation of $\mathrm{Mn}$ in the $\mathrm{ZnS}$ shell is evidenced by X-ray diffractograms, as shown in Figure 2. The nanocrystals retain their sphalerite structure, with narrow diffraction peaks indicative of large monocrystalline nanoparticles. Using Scherrer's law (see Materials and Methods section), the derived crystallite size is around $7 \mathrm{~nm}$ for all samples. The diffraction peaks deviates from pure $\mathrm{ZnS}$ towards $\mathrm{MnS}$ at smaller angles with increasing Mn content in the injection solution. The position of the XRD peaks may be used to determine the final Mn content in the nanocrystals using Vegard's law. In the range of $2 \%$ to $30 \%$ of Mn compared to the total cation content $(\mathrm{Zn}+\mathrm{Mn})$, the $\mathrm{Mn}$ proportion measured in the final nanocrystals using XRD closely follows the composition of the injection solution. This was confirmed by elemental analysis using EDS on nanocrystal powders, as shown in Table S1 in Electronic Supplementary Information.

In addition, the incorporation of manganese in the $\mathrm{ZnS}$ shell is probed using electron paramagnetic resonance (EPR). EPR spectra for samples with different manganese contents are presented in Figure 3. We observed a classical structure for manganese in zinc sulfide. ${ }^{35}$ At very low Mn concentration, up to $2 \%$, these spectra exhibit a six-line hyperfine structure, with a $71 \mathrm{G}$ splitting at $9.7 \mathrm{GHz}$ corresponding to $\mathrm{Mn}$ in $\mathrm{ZnS}{ }^{35}$ This structure gradually disappears when the manganese content is increased, due to $\mathrm{Mn}-\mathrm{Mn}$ interactions. ${ }^{36}$ Magnetometry measurements at room temperature show a paramagnetic behavior for all samples (see Figure S2 in ESI). This, together with the above results, confirms that $\mathrm{Mn}$ is incorporated inside the shell and not only adsorbed at the surface of the QDs.

Incorporation of $\mathrm{Mn}$ in the shell did not influence the size or the shape of the nanocrystals: TEM images (Figure 4a) show nearly spherical nanoparticles of around $9 \pm 3 \mathrm{~nm}$ in diameter (see figure S3(c) in ESI for size distribution), corresponding to a 2-3 nm $\mathrm{Mn}_{\mathrm{x}} \mathrm{Zn}_{1-\mathrm{x}} \mathrm{S}$ shell thickness. Diffraction patterns observed by high resolution TEM confirm the cubic sphalerite crystalline structure of the core-shell nanocrystals (Figure S3 in ESI).

We investigated the influence of $\mathrm{Mn}: \mathrm{Zn}$ ratio on the optical properties of $\mathrm{Zn}-\mathrm{Cu}-\mathrm{In}-\mathrm{S} / \mathrm{Zn}_{1}$ ${ }_{\mathrm{x}} \mathrm{Mn}_{\mathrm{x}} \mathrm{S} \mathrm{QD}$. These properties remain quite similar to $\mathrm{Zn}-\mathrm{Cu}-\mathrm{In}-\mathrm{S} / \mathrm{ZnS}$ QDs, as shown in Figure 4b and Figure S4 in ESI. Absorption and photoluminescence excitation spectra show a high absorption at small wavelength, below $350 \mathrm{~nm}$, which reflects the growth of a thick $\mathrm{ZnS}$ shell. Similarly to Zn-Cu-In-S/ZnS QDs, the growth of the shell induces a small blue shift due to a limited incorporation of zinc in the core. No systematic additional shift was observed for different Mn content. For these QDs, the bandgap energy is lower than the ${ }^{4} \mathrm{~T}_{1}-{ }^{6} \mathrm{~A}_{1}$ ligandfield $\mathrm{Mn}$ transition, ${ }^{37}$ which prescribes energy transfer from the QD bandgap to the $\mathrm{Mn}$ centers, so that the QDs retain their core emission properties. ${ }^{38}$

\section{Relaxivity measurements.}

There are mainly two strategies to transfer quantum dots into water: encapsulation and ligand exchange. ${ }^{39}$ The encapsulation process requires the use of amphiphilic molecules, whose hydrophobic part interacts with the initial hydrophobic ligands of the QD and hydrophilic part ensures water solubility and colloidal stability. This strategy possesses the advantage of an excellent preservation of the fluorescence properties, since the QD surface chemistry is kept unmodified. Their PL stability in water is also superior, as the hydrophobic layer prevents 
water, ions and small solutes from accessing the QD surface. However, this would potentially limit the MRI response of these probes, as water protons would not be able to reach the close proximity of the paramagnetic $\mathrm{Mn}$ ions located in the $\mathrm{ZnS}$ shell. In contrast, exchanging the original hydrophobic ligand with new hydrophilic ligands may decrease the PL quantum yields of the QDs due to suboptimal surface passivation and oxidation. However, it enhances proton access to the QD surface, which should translate into better MRI response. Since we expect that the fluorescence sensitivity achieved by our QDs will be higher than for MRI, we chose to use the latter strategy. In addition, ligand exchange generally offers more compact probes compared to encapsulation strategies. We therefore exchanged the original (xanthogenates, oleylamine and/or oleate) ligands by polyethylene glycol (PEG) modifieddihydrolipoic acids (DHLA-PEG) ${ }^{27}$ These ligands provide colloidal stability in a wide range of buffers with a reduced non-specific biomolecule adsorption. QDs were then purified using ultrafiltration to remove excess of unbound ligands and possibly desorbed ions, as well as using centrifugation to remove small aggregates. The optical properties remained similar in water (see Figure S5 in ESI) and we obtained quantum yields up to $20 \%$. The hydrodynamic radius of our QDs capped with DHLA-PEG was measured by DLS and was found to be $10.8 \pm 0.7 \mathrm{~nm}$ (see figure S6 in ESI), consistently with the size of our QDs and of the DHLAPEG ligands. Zeta potential measurement indicated that our probes were neutral $(0.5 \pm 0.2 \mathrm{mV})$, as expected from PEG-coated nanoparticles.

We then measured the $\mathrm{r}_{1}$ relaxivity of $\mathrm{Zn}-\mathrm{Cu}-\mathrm{In}-\mathrm{S} / \mathrm{Zn}_{1-\mathrm{x}} \mathrm{Mn}_{\mathrm{x}} \mathrm{S}$ QDs with different manganese contents using ${ }^{1} \mathrm{H}$ NMR in pure water under a $7 \mathrm{~T}$ static magnetic field at $300 \mathrm{~K}$. The relaxation rate of water protons increased linearly with the QD concentration for all samples (see Figure S7 in ESI). We measured the absolute concentration of manganese, indium and zinc using ICP-AES, then normalized by the Mn concentration to derive relaxivity values in $\mathrm{mM}(\mathrm{Mn})^{-1} \mathrm{~s}^{-}$ ${ }^{1}$, as shown in Figure 5. At low Mn content, we observe a strong increase in relaxivity with increasing $\mathrm{Mn}$ content, from about $0.01 \mathrm{mM}(\mathrm{Mn})^{-1} \mathrm{~s}^{-1}$ for QDs containing $1 \% \mathrm{Mn}$ to 0.5 $\mathrm{mM}(\mathrm{Mn})^{-1} \mathrm{~s}^{-1}$ for QDs containing $20 \% \mathrm{Mn}$ at $7 \mathrm{~T}$. This increase suggests that several $\mathrm{Mn}$ participates cooperatively in the relaxation dynamics of water protons diffusing near the surface of the nanoparticle: when the Mn concentration is higher, each Mn participates more efficiently to the water relaxivity. Interestingly, the optimal Mn concentration in $\mathrm{ZnS}, 20 \%$, is above the solubility of $\mathrm{MnS}$ in $\mathrm{ZnS}$ at the synthesis temperature (7.5\% for bulk materials). ${ }^{40}$ It is unclear whether our continuous growth method actually leads to epitaxial growth of small $\mathrm{MnS}$ nanoclusters or if the Mn ions are dispersed homogeneously in the shell. While bulk $\mathrm{MnS}$ is antiferromagnetic, ${ }^{41}$ very small $\mathrm{MnS}$ clusters may contain uncompensated spins at their boundaries, which could interact with nearby water protons and accelerate their relaxation. With more concentrated samples (such as $\mathrm{Zn}_{0.75} \mathrm{Mn}_{0.25} \mathrm{~S}$ ), the effective relaxivity per mmol of manganese decreases. This may be due to the increase of antiferromagnetic coupling between neighbouring manganese atoms. ${ }^{42}$

With respect to the application of our Mn-doped QDs to MRI, it is interesting to consider their "per QD-relaxivity" in $\mathrm{mM}(\mathrm{QD})^{-1} \mathrm{~s}^{-1}$, obtained by multiplying the per Mn-relaxivity by the number of Mn per QD, as determined by elemental analysis. This will indeed dictate the local concentration of doped QDs needed to obtain a T1 contrast in a specific tissue. Figure 5 
shows that the per-QD relaxivity first strongly increases with the doping rate, since both the per-Mn relaxivity and the number of $\mathrm{Mn}$ per QD increase. The optimal sample, corresponding to a $\mathrm{Zn}_{0.85} \mathrm{Mn}_{0.15} \mathrm{~S}$ shell, presents a $\mathrm{r}_{1}$ value of $0.5 \mathrm{mM}(\mathrm{Mn})^{-1} \mathrm{~s}^{-1}$ and $1500 \mathrm{mM}(\mathrm{QD})^{-1} \mathrm{~s}^{-1}$ at $7 \mathrm{~T}$. The per-Mn relaxivity is lower than for single ion probes such as Gd-DTPA $\left(3.1 \mathrm{mM}^{-1} \mathrm{~s}^{-1}\right.$ at $7 \mathrm{~T}^{43}$ and slightly lower than previously reported Mn-doped $\mathrm{Si}$ QDs ${ }^{44}, \mathrm{Zn}_{0.9} \mathrm{Mn}_{0.1} \mathrm{~S}$ nanocrystals ${ }^{45}$ and $\mathrm{CdSe} / \mathrm{Zn}_{0.94} \mathrm{Mn}_{0.06} \mathrm{~S}_{\mathrm{QDs}}{ }^{23}$. We attribute this difference to the fact that the effect of $\mathrm{Mn}$ ions on water protons decreases with the distance to the shell surface, so that $\mathrm{Mn}$ ions deeply buried in the shell do not contribute much to the overall relaxivity. On the other hand, our thick shell allows the incorporation of much more Mn ions (3000 Mn/QD for the optimal sample), leading to a maximal relaxivity of $1500 \mathrm{mM}(\mathrm{QD})^{-1} \mathrm{~s}^{-1}$ at $7 \mathrm{~T}$. This high relaxivity should provide a high detection sensitivity for low density biomolecular markers.

Ideally, QDs for in vivo imaging should not only emit in the NIR transparency window (700$900 \mathrm{~nm}$ ) but also be capable to efficiently absorb light in the same region, so that excitation light could efficiently penetrate the tissue and excite the probes. If we select for this purpose an excitation wavelength around $700 \mathrm{~nm}$, optimal NIR QDs should emit further than the 700$750 \mathrm{~nm}$ range obtained for our $\mathrm{CuInS}_{2}$-based probes in order to optimize their absorption cross-section at $700 \mathrm{~nm}$ and be able to efficiently discriminate between excitation back reflection and fluorescence emission. We therefore chose to synthesize $\mathrm{Zn}$-Cu-In$\mathrm{Se} / \mathrm{Zn}_{0.8} \mathrm{Mn}_{0.2} \mathrm{~S}$ core/shell QDs, based on previously reported protocols for cores ${ }^{16}$ and protocols similar to those used for $\mathrm{Zn}-\mathrm{Cu}-\mathrm{In}-\mathrm{S}$ for the $\mathrm{Zn}_{1-\mathrm{x}} \mathrm{Mn}_{\mathrm{x}} \mathrm{S}$ shell. This allowed us to obtain Mn-doped QDs with smaller shell thicknesses (around 1.5nm) and manganese content (see table S1 in ESI), but with an $800 \mathrm{~nm}$-centered emission (see Figure S8 in ESI), which was better adapted for in vivo imaging. The relaxivity of $\mathrm{Zn}-\mathrm{Cu}-\mathrm{In}-\mathrm{Se} / \mathrm{Zn}_{0.86} \mathrm{Mn}_{0.14} \mathrm{~S}$ QDs was estimated to be $110 \mathrm{mM}(\mathrm{QD})^{-1} \mathrm{~s}^{-1}$ and $0.13 \mathrm{mM}(\mathrm{Mn})^{-1} \mathrm{~s}^{-1}$. The relaxivity per $\mathrm{Mn}$ atom (Fig. 5, inverted triangle) is comparable with the ones obtained with $\mathrm{CuInS}_{2}$ cores. Nonetheless, the per QD relaxivity (Fig.5, diamond) is lower due to a smaller number of Mn ions incorporated in each QD (around $1000 \mathrm{Mn} / \mathrm{QD}$ ) and a smaller surface of QDs.

\section{Mn leaching and cytotoxicity}

To ensure a prolonged colocalization of the MRI and fluorescence signals and limit toxicity due to $\mathrm{Mn}$ leaching, the paramagnetic Mn dopants must remain inside the QD nanocrystals even after prolonged exposition in a biological medium. $\mathrm{Zn}-\mathrm{Cu}-\mathrm{In}-\mathrm{Se} \quad / \mathrm{Zn}_{0.8} \mathrm{Mn}_{0.2} \mathrm{~S} \quad$ QDs were incubated in culture medium at $37^{\circ} \mathrm{C}$ and the released $\mathrm{Mn}$ ions were quantified by colorimetry. The release of $\mathrm{Mn}$ ions was indeed found to be extremely slow: $(1.3 \pm 0.8) \%$ after 3 days and (2.6 \pm 0.9$) \%$ after 7 days.

We investigated the cytotoxicity of our probes with or without $\mathrm{Mn}$ in the shell using a common colorimetric MTT assay after a $24 \mathrm{~h}$ incubation (Figure S9 in ESI). Interestingly, the presence of manganese in the QD shell does not increase significantly the cytotoxicity of our QDs, even at millimolar concentrations of Mn. Cellular viability remains above $80 \%$ for QD concentrations up to $1 \mu \mathrm{M}$, which shows the low toxicity of these QD probes. In comparison, other QDs reported a much stronger toxicity with $\mathrm{IC}_{50}$ values around $100 \mathrm{nM}$, such as 
CdSe/ZnS $(45 \mathrm{nM}),{ }^{46} \mathrm{CdTe} / \mathrm{ZnS}(100 \mathrm{nM}){ }^{47}$ or InAs/InP/ZnS $(\approx 100 \mathrm{nM}){ }^{48}$ This lower toxicity may be attributable to the large inert $\mathrm{ZnS}$ shell and to the virtual absence of released free $\mathrm{Mn}$ ions from the QDs at this timescale. We also note that in vitro toxicity results cannot be directly extrapolated to in vivo toxicity, since it depends on the overall biodistribution and organ specific doses. ${ }^{49}$ For example, an absence of acute toxicity has been demonstrated after intravenous injection of relatively high doses of CdSe-based QDs. ${ }^{11}$ Since our Cd-free QDs show lower in vitro toxicity, we assume that they will also present limited in vivo toxicity, even though a comprehensive in vivo study is required to fully understand the in vivo biological response to our nanoprobes.

\section{In vivo imaging.}

As a simple proof-of-principle, we chose to demonstrate detection of regional lymph nodes in mice. This required no further functionalization for specific targeting of the QDs, since nanoparticles injected subcutaneously are partly drained through lymph vessels and captured by macrophages in the lymph nodes. In addition, lymph node detection represents a potential clinical application of such probes, as lymph node resection is a common diagnostic procedure in the treatment of breast cancer. A solution containing $4 \mathrm{nmol}$ of $\mathrm{Cu}$-In$\mathrm{Se} / \mathrm{Zn}_{0.88} \mathrm{Mn}_{0.12} \mathrm{~S}$ QDs emitting at $810 \mathrm{~nm}$ and coated with DHLA-PEG was prepared in phosphate buffer saline solution (PBS) and injected in the anterior left paw of a mouse. As previously demonstrated with other PEG-coated NIR emitting QDs, the probes migrated very rapidly to the regional lymph nodes. ${ }^{15}$ Using MRI, a strong signal enhancement was clearly visible on T1-weighted images, acquired 20 min after QD injection (Fig. 6), compared to preinjection images. Near infrared fluorescence images acquired a few minutes later (Figure 6c) clearly show the two regional lymph nodes previously detected in MRI. Here, the injection point was hidden to increase the contrast. However, the nodes were also visible without hiding it, as shown in Figure S10 in ESI. These results demonstrate the good colocalization of MR and NIRF contrast in the regional lymph nodes due to the uptake of the Mn-doped QDs.

\section{CONCLUSION}

In this work, we have described the synthesis of core/shell $\mathrm{CuIn}(\mathrm{S}, \mathrm{Se})_{2} / \mathrm{Zn}_{1-\mathrm{x}} \mathrm{Mn}_{\mathrm{x}} \mathrm{S}$ bimodal probes for both near infrared fluorescence imaging and MRI, based on low-toxicity materials. By varying the size and composition of the cores, we were able to tune the emission wavelength of these QDs throughout the "therapeutic window", the spectral range corresponding to minimum absorption and diffusion of blood and tissues. The growth of a thick shell of $\mathrm{Zn}_{1-\mathrm{x}} \mathrm{Mn}_{\mathrm{x}} \mathrm{S}$ on fluorescent cores not only preserves their fluorescence in water but also confers a paramagnetic character to our probes. Optimization of the nanoparticle size and $\mathrm{Mn}$ content leads to $\mathrm{r}_{1}$ relaxivities in water ranging from 1 to $1500 \mathrm{mM}(\mathrm{QD})^{-1} \mathrm{~s}^{-1}$, allowing sensitive MR and NIRFI detection. Finally, we have demonstrated the use of these probes in vivo for imaging the regional lymph nodes in mice in both NIRFI and MRI. These probes represent promising tools for in vivo biological and biomedical imaging due to their high sensitivities and to the well-developed toolbox available for QD functionalization. Further biodistribution and toxicity studies will be required before translating these probes to the medical field. 


\section{Acknowledgements}

The authors would like to thank X. Xu for help with TEM, G. Lang for EPR, B. Bresson for NMR and B. Leridon for SQUID. Part of this work was supported by a SESAME grant from Région Ile-de-France and by the Investissement d'avenir project NanoCTC from the Ministère de l'enseignement supérieur et de la recherche (France).

\section{References}

1. 1 R. J. Gillies, J. Cell. Biochem., 2002, 87, S39, 231-238

2. T. F. Massoud and S. S. Gambhir, Genes Dev., 2003, 17, 545-80.

3. R. Weissleder and M. J. Pittet, Nature, 2008, 452, 580-9.

4. J. Cheon and J.-H. Lee, Acc. Chem. Res., 2008, 41, 1630-40.

5. E. T. Ahrens and J. W. M. Bulte, Nat. Rev. Immunol., 2013, 13, 755-763.

6. X. Michalet, F. F. Pinaud, L. a Bentolila, J. M. Tsay, S. Doose, J. J. Li, G. Sundaresan, a M. Wu, S. S. Gambhir, and S. Weiss, Science (80-. )., 2005, 307, 538-44.

7. H. Mattoussi, G. Palui, and H. Bin Na, Adv. Drug Deliv. Rev., 2012, 64, 138-66.

8. S. Kim, Y. T. Lim, E. G. Soltesz, A. M. De Grand, J. Lee, A. Nakayama, J. A. Parker, T. Mihaljevic, R. G. Laurence, D. M. Dor, L. H. Cohn, M. G. Bawendi, and J. V Frangioni, Nat. Biotechnol., 2004, 22, 93-7.

9. E. Cassette, M. Helle, L. Bezdetnaya, F. Marchal, B. Dubertret, and T. Pons, Adv. Drug Deliv. Rev., 2013, 65, 719-31.

10. J. Mobley and T. Vo-Dinh, in Biomedical Photonics Handbook, ed. T. Vo-Dinh, CRC Press, Boca Raton, FL, 2003.

11. L. Ye, K. Yong, L. Liu, I. Roy, R. Hu, J. Zhu, H. Cai, W. Law, J. Liu, K. Wang, J. Liu, Y. Liu, Y. Hu, X. Zhang, M. T. Swihart, and P. N. Prasad, Nat. Nanotechnol., 2012, 7, 453-458.

12. X. Li, Y. He, S. S. Talukdar, and M. T. Swihart, Langmuir, 2003, 19, 8490-8496.

13. F. Erogbogbo, K. Yong, I. Roy, R. Hu, W. Law, W. Zhao, H. Ding, F. Wu, R. Kumar, M. T. Swihart, and P. N. Prasad, ACS Nano, 2011, 5, 413-23.

14. L. Li, T. J. Daou, I. Texier, T. T. Kim Chi, N. Q. Liem, and P. Reiss, Chem. Mater, 2009, 21, 2422-2429.

15. T. Pons, E. Pic, N. Lequeux, E. Cassette, L. Bezdetnaya, F. Guillemin, F. Marchal, and B. Dubertret, ACS Nano, 2010, 4, 2531-2538. 
16. E. Cassette, T. Pons, C. Bouet, M. Helle, L. Bezdetnaya, F. Marchal, and B. Dubertret, Chem. Mater., 2010, 22, 6117-6124.

17. K.-T. Yong, I. Roy, R. Hu, H. Ding, H. Cai, J. Zhu, X. Zhang, E. J. Bergey, and P. N. Prasad, Integr. Biol., 2010, 2, 121-9.

18. J.-C. Hsu, C.-C. Huang, K.-L. Ou, N. Lu, F.-D. Mai, J.-K. Chen, and J.-Y. Chang, J. Mater. Chem., 2011, 21, 19257.

19. C. Cheng, K. Ou, W. Huang, J. Chen, J. Chang, and C. Yang, ACS Appl. Mater. Interfaces, 2013, 5, 4389-400.

20. F. Ducongé, T. Pons, C. Pestourie, L. Hérin, B. Thézé, K. Gombert, B. Mahler, F. Hinnen, B. Kühnast, F. Dollé, B. Dubertret, and B. Tavitian, Bioconjug. Chem., 2008, 19, 1921-6.

21. E. Giovanelli, E. Muro, G. Sitbon, M. Hanafi, T. Pons, B. Dubertret, and N. Lequeux, Langmuir, 2012, 28, 15177-84.

22. R. Bhargava, D. Gallagher, X. Hong, and A. Nurmikko, Phys. Rev. Lett., 1994, 72, 416-419.

23. S. Wang, B. R. Jarrett, S. M. Kauzlarich, and A. Y. Louie, J. Am. Chem. Soc., 2007, 129, 3848-3856.

24. G. Manna, S. Jana, R. Bose, and N. Pradhan, J. Phys. Chem. Lett., 2012, 3, 25282534.

25. Q. Liu, R. Deng, X. Ji, and D. Pan, Nanotechnology, 2012, 23, 255706.

26. B. Lin, X. Yao, Y. Zhu, J. Shen, X. Yang, H. Jiang, and X. Zhang, New J. Chem., 2013, 37, 3076-3083.

27. B. C. Mei, K. Susumu, I. L. Medintz, J. B. Delehanty, T. J. Mountziaris, and H. Mattoussi, J. Mater. Chem., 2008, 18, 4949.

28. F. B. Serrat, Mikrochim. Acta, 1998, 129, 77-80.

29. N. A. Monteiro-Riviere, A. O. Inman, and L. W. Zhang, Toxicol. Appl. Pharmacol., 2009, 234, 222-235.

30. S. Wang, H. Yu, and J. K. Wickliffe, Toxicol. Vitr., 2011, 25, 2147-51.

31. J. J. Li, Y. A. Wang, W. Guo, J. C. Keay, T. D. Mishima, M. B. Johnson, and X. Peng, J. Am. Chem. Soc., 2003, 125, 12567-75.

32. J. Park and S.-W. Kim, J. Mater. Chem., 2011, 21, 3745-3750.

33. T. K. C. Tran, Q. P. Le, Q. L. Nguyen, L. Li, and P. Reiss, Adv. Nat. Sci. Nanosci. Nanotechnol., 2010, 1, 025007. 
34. Y. Yang, O. Chen, A. Angerhofer, and Y. C. Cao, J. Am. Chem. Soc., 2008, 130, 15649-61.

35. T. Kennedy, E. Glaser, P. Klein, and R. Bhargava, Phys. Rev. B, 1995, 52, R14356R14359.

36. Y. Ishikawa, J. Phys. Soc. Japan, 1966, 21, 1473-1481.

37. D. Langer and H. Richter, Phys. Rev., 1966, 146, 554-557.

38. R. Beaulac, P. I. Archer, X. Liu, S. Lee, G. M. Salley, M. Dobrowolska, J. K. Furdyna, and D. R. Gamelin, Nano Lett., 2008, 8, 1197-201.

39. S. B. Brichkin and E. V. Chernykh, High Energy Chem., 2011, 45, 1-12.

40. C. Sombuthawee, S. B. Bonsall, and F. A. Hummel, J. Solid State Chem., 1978, 25, 391-399.

41. L. Corliss, N. Elliott, and J. Hastings, Phys. Rev., 1956, 104, 924-928.

42. S. H. Koenig and R. D. Brown, Prog. Nucl. Magn. Reson. Spectrosc., 1990, 22, 487567.

43. C. Kalavagunta, S. Michaeli, and G. J. Metzger, Contrast Media Mol. Imaging, 2014, 9, 169-176.

44. C. Tu, X. Ma, P. Pantazis, S. M. Kauzlarich, and A. Y. Louie, J. Am. Chem. Soc., 2010, 132, 2016-23.

45. M. Gaceur, M. Giraud, M. Hemadi, S. Nowak, N. Menguy, J. P. Quisefit, K. David, T. Jahanbin, S. Benderbous, M. Boissière, and S. Ammar, J. Nanoparticle Res., 2012, 14, 932938.

46. S. Deka, A. Quarta, M. G. Lupo, A. Falqui, S. Boninelli, C. Giannini, G. Morello, M. De Giorgi, G. Lanzani, C. Spinella, R. Cingolani, T. Pellegrino, and L. Manna, J. Am. Chem. Soc., 2009, 131, 2948-58.

47. Y. Su, Y. He, H. Lu, L. Sai, Q. Li, W. Li, L. Wang, P. Shen, Q. Huang, and C. Fan, Biomaterials, 2009, 30, 19-25.

48. R. Xie, K. Chen, X. Chen, and X. Peng, Nano Res., 2008, 1, 457-464.

49. K. M. Tsoi, Q. Dai, B. A. Alman, and W. C. W. Chan, Acc. Chem. Res., 2013, 46, $662-71$. 


\section{FIGURES}
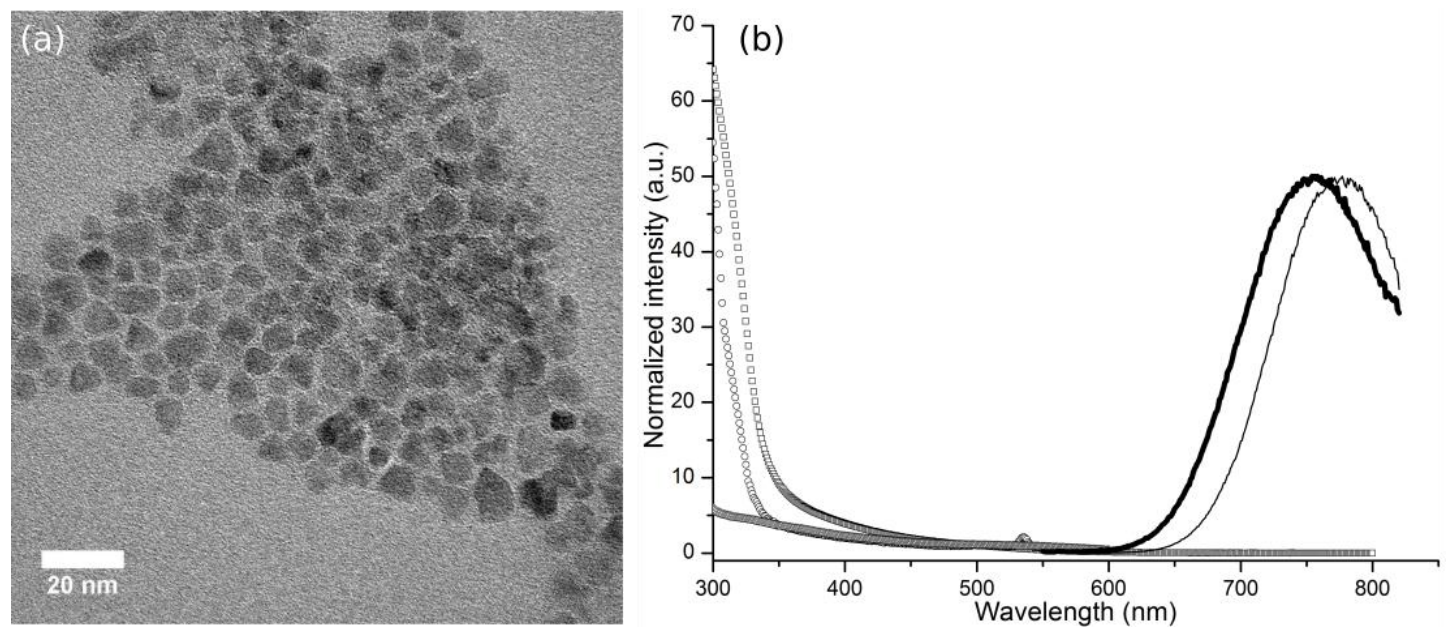

Figure 1 a) TEM images of Zn-Cu-In-S/ZnS core/shell QDs; b) Normalized PL spectra of Zn-Cu-In-S core (gray) and $\mathrm{Zn}-\mathrm{Cu}-\mathrm{In}-\mathrm{S} / \mathrm{ZnS}$ core/shell QDs (black), absorbance spectra of core (triangles) and core-shell (squares), and PLE spectrum of Zn-Cu-In-S/ZnS core/shell QDs (circles).

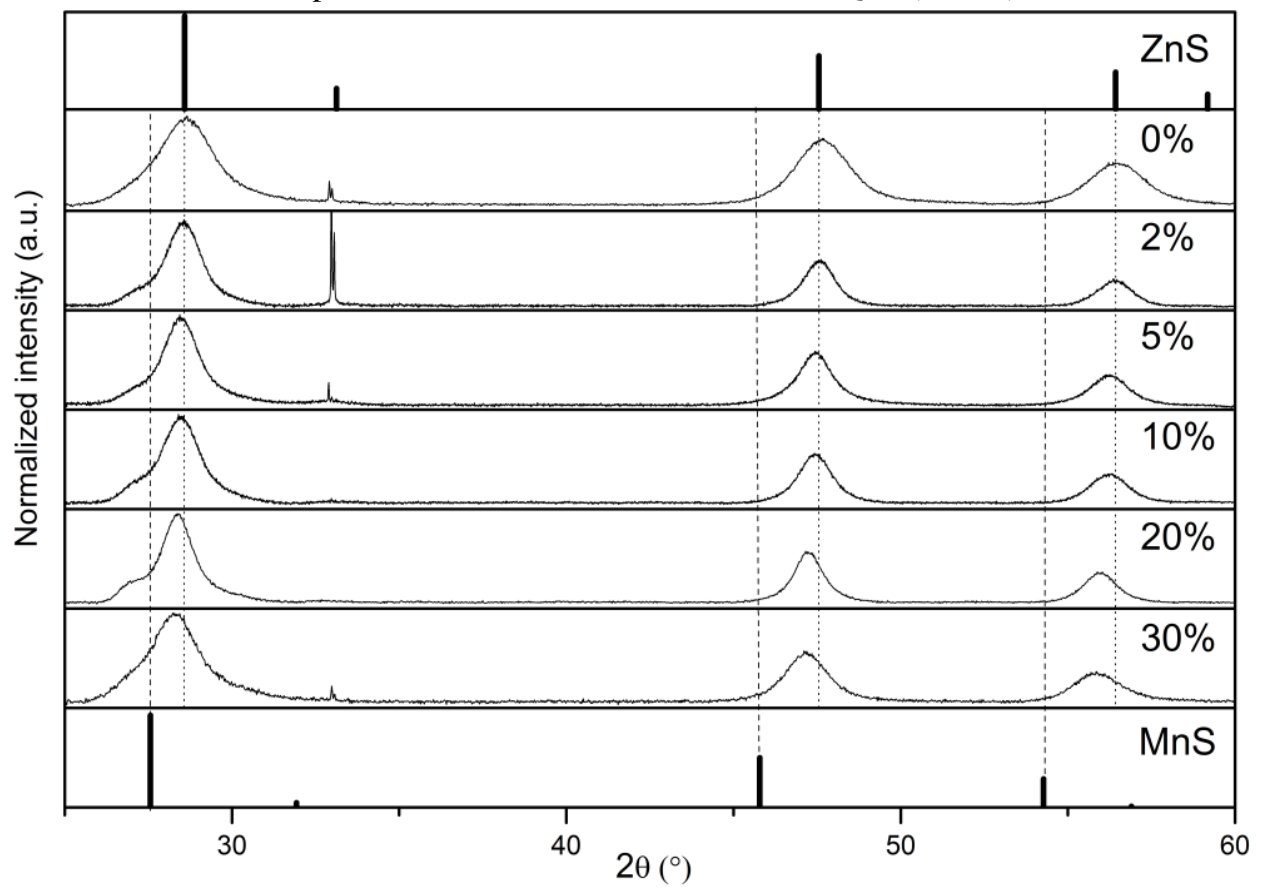

Figure 2 XRD patterns obtained for different Mn concentrations in the injection solution. Patterns for zinc blende ZnS (JCPDS 03-065-5476) and MnS (JCPDS 03-065-2884) are indicated for reference. 


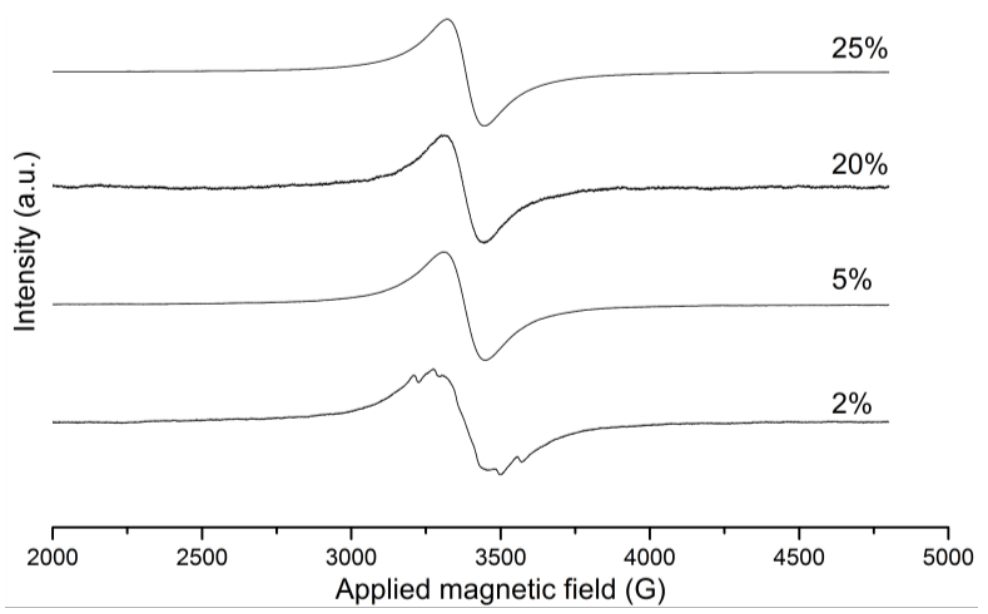

Figure 3 EPR spectra of $\mathrm{Zn}-\mathrm{Cu}-\mathrm{In}-\mathrm{S} / \mathrm{Zn}_{1-\mathrm{x}} \mathrm{Mn}_{\mathrm{x}} \mathrm{S}$ QDs obtained for various Mn contents

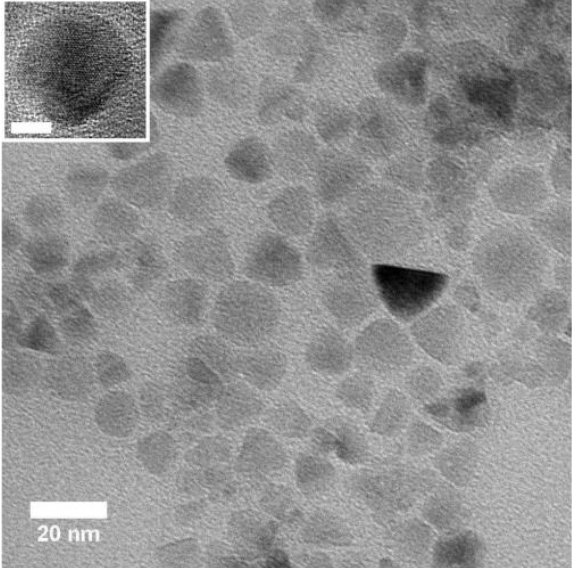

(a)

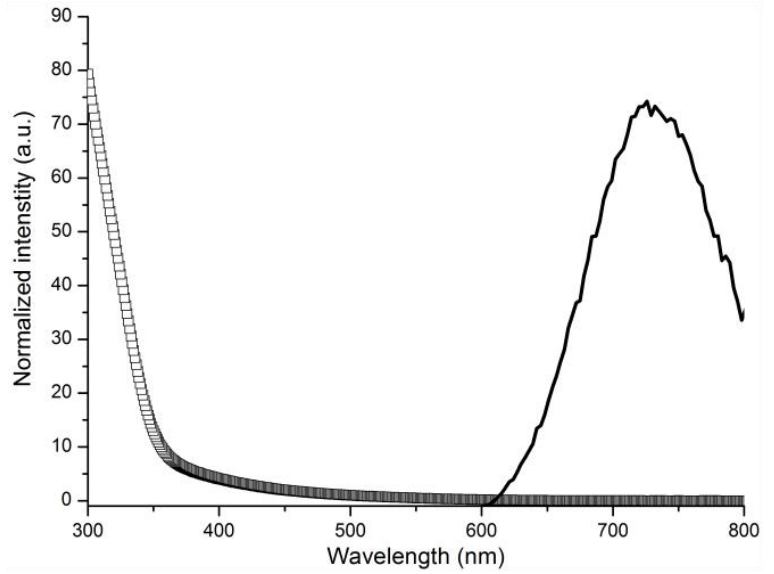

(b)

Figure 4 : a) Typical TEM image (Inset: HRTEM image, scale bar: 5nm), b) Absorbance (squares) and PL (black) spectra of $\mathrm{Zn}-\mathrm{Cu}-\mathrm{In}-\mathrm{S} / \mathrm{Zn}_{1-\mathrm{x}} \mathrm{Mn}_{\mathrm{x}} \mathrm{S}$ core/shell QDs 


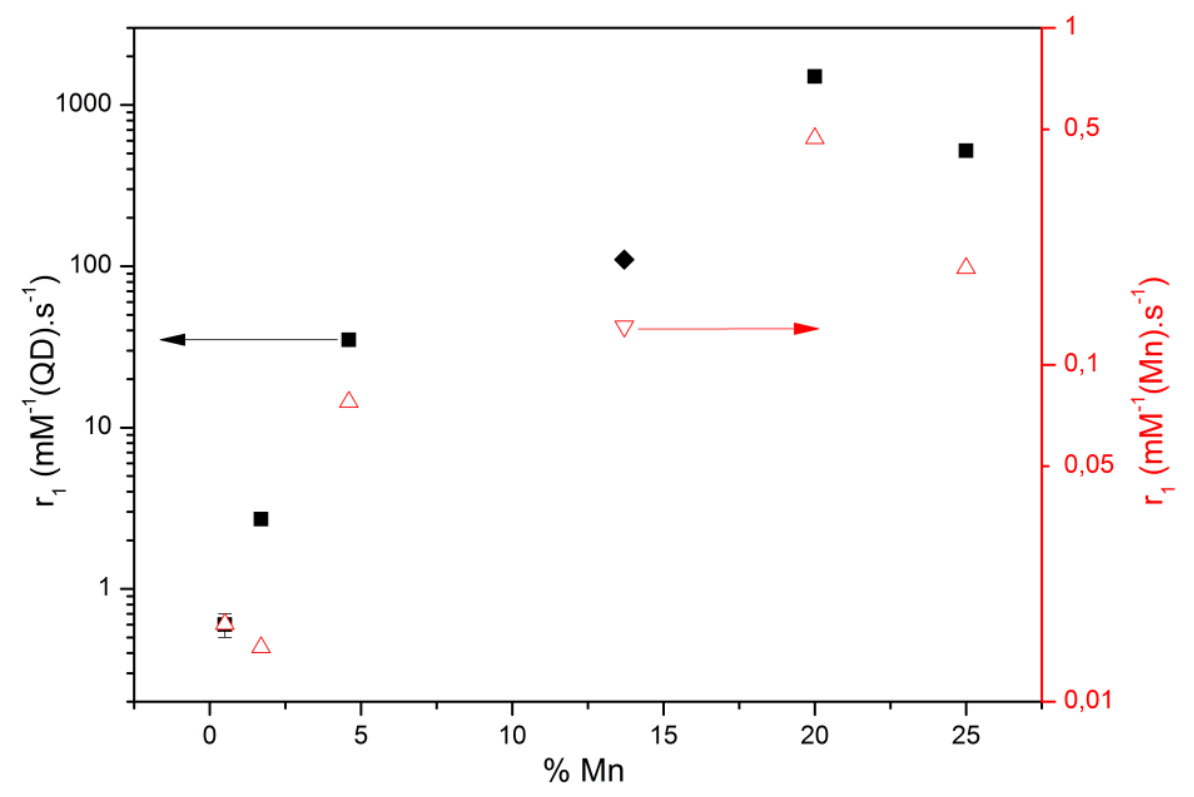

Figure 5 Longitudinal relaxivity $\mathrm{r}_{1}$ of $\mathrm{Zn}$-Cu-In-(S,Se)/ $\mathrm{Zn}_{1-\mathrm{x}} \mathrm{Mn}_{\mathrm{x}} \mathrm{S}$ QDs normalized to the Mn (S: triangles; Se: inverted triangles, right axis) or QD (S: squares; Se: diamonds, left axis) concentration as a function of the Mn content in the shell.
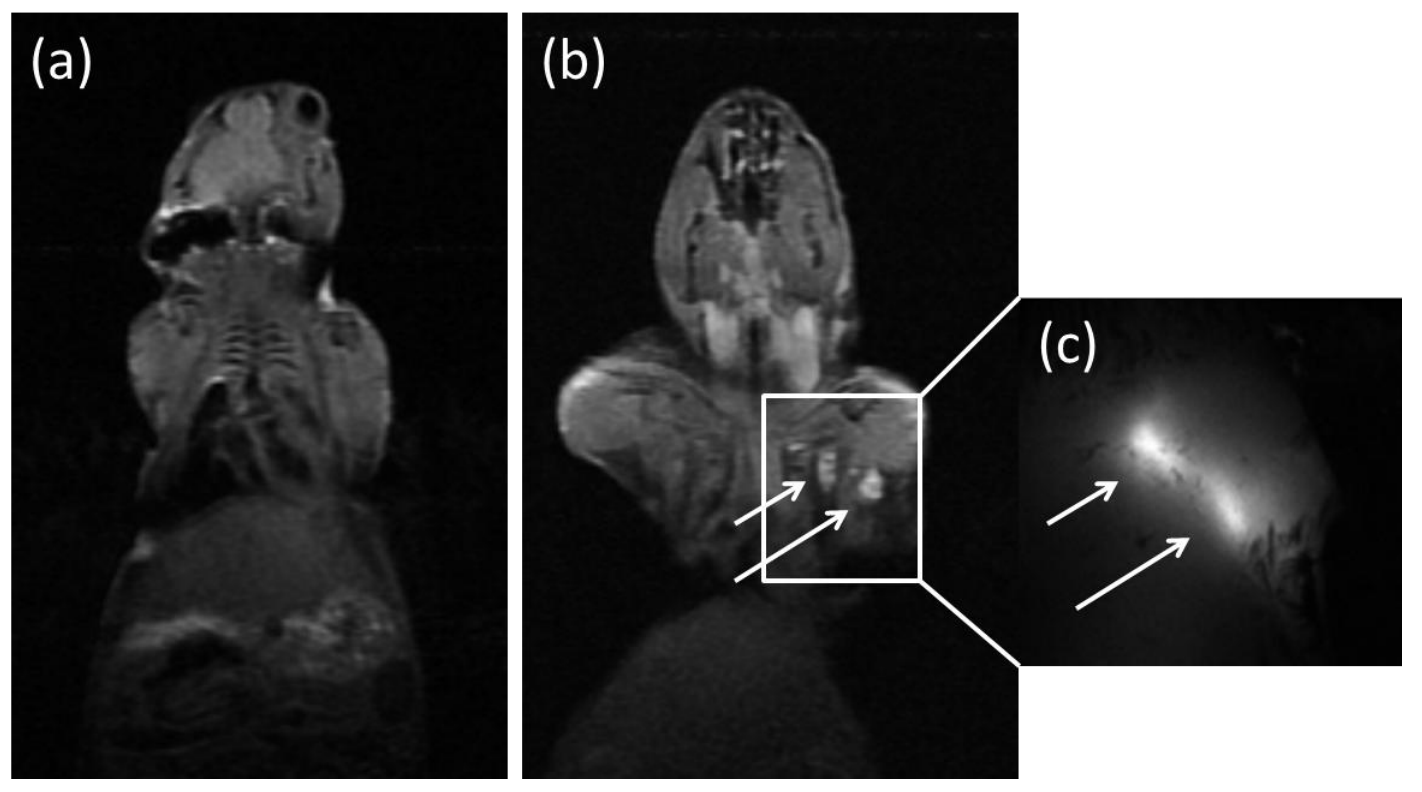

Figure 6 T1-weighted MRI images of a mouse before (a) and after (b) injection of a solution of $\mathrm{Zn}$-Cu-In$\mathrm{Se} / \mathrm{Zn}_{0.9} \mathrm{Mn}_{0.1} \mathrm{~S}$ QDs and the corresponding NIRF image (c) 


\section{Electronic Supporting Information}

\section{Fluorescence lifetime measurements}
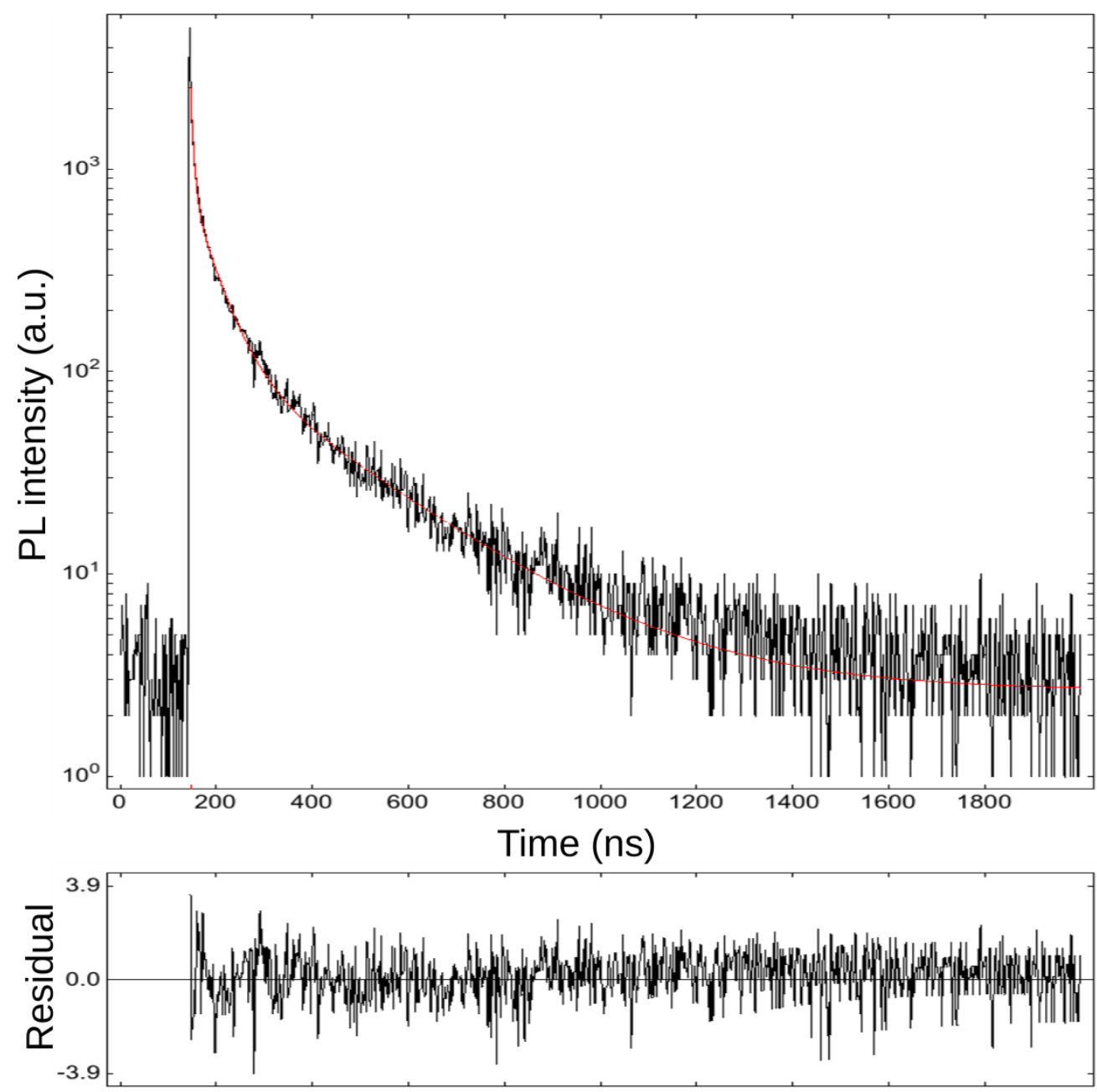

Figure S1 Photoluminescence intensity as a function of time fitted with a triexponential decay curve (red). The three lifetimes are $5.9 \pm 0.3 \mathrm{~ns}, 48 \pm 2 \mathrm{~ns}$ and $253 \pm 6 \mathrm{~ns}$.

Table S1 Manganese content (in \%) of various quantum dots determined by XRD, EDX and ICP-AES

\begin{tabular}{l|l|l|l|l|l|l} 
Core & \multicolumn{5}{|c|}{$\mathrm{CuInS}_{2}$} & $\mathrm{CuInSe}_{2}$ \\
\hline Injection solution & 2 & 5 & 10 & 20 & 30 & 20 \\
\hline XRD & $3.4 \pm 0.3$ & $7 \pm 2$ & $8 \pm 2$ & $19 \pm 2$ & $24 \pm 2$ & $12 \pm 2$ \\
\hline EDX & $1.2 \pm 0.2$ & $5 \pm 2$ & $5 \pm 2$ & $17 \pm 2$ & $12 \pm 2$ & $15 \pm 3$ \\
\hline ICP-AES & $1.7 \pm 0.2$ & $4.6 \pm 0.5$ & $4.6 \pm 0.6$ & $20 \pm 3$ & $25 \pm 3$ & $13.7 \pm 0.1$
\end{tabular}




\section{Magnetic characterization}

Samples are prepared by drying a QD solution in a capsule and magnetic moment as a function of applied magnetic field are recorded using a Quantum Design VSM at room temperature.

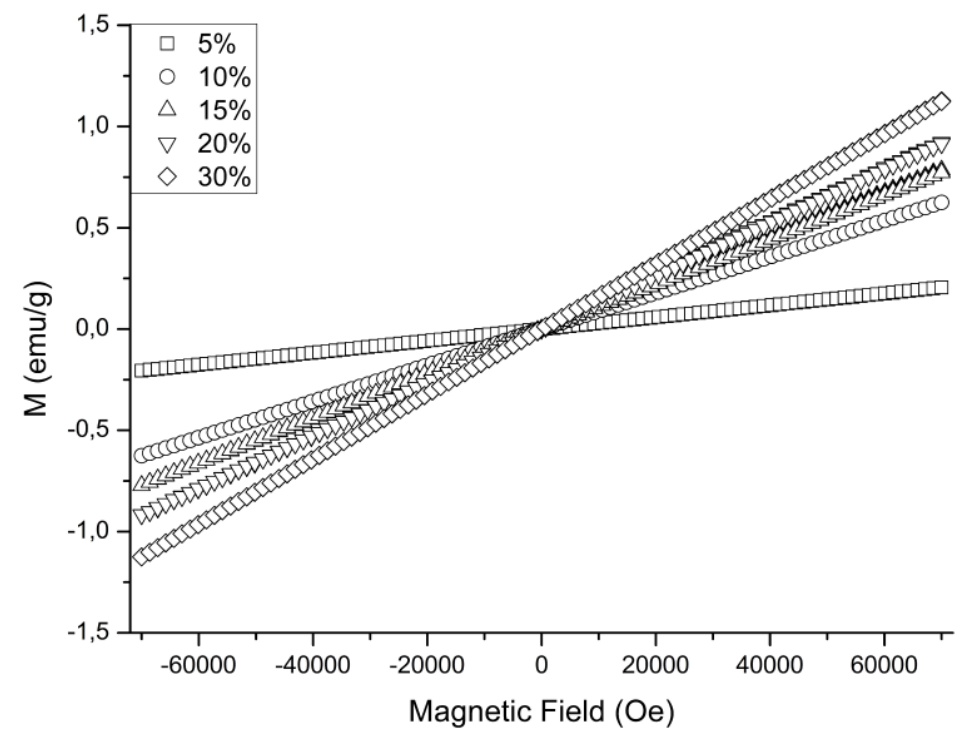

Figure S2 Room temperature magnetization curves of $\mathrm{Zn}-\mathrm{Cu}-\mathrm{In}-\mathrm{S} / \mathrm{Zn}_{1-\mathrm{x}} \mathrm{Mn}_{\mathrm{x}} \mathrm{S}$ QDs for different $\mathrm{Mn}$ shell content

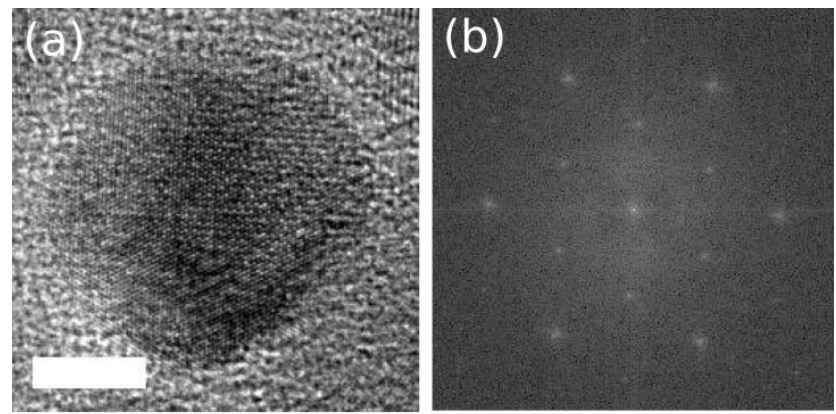

(c)

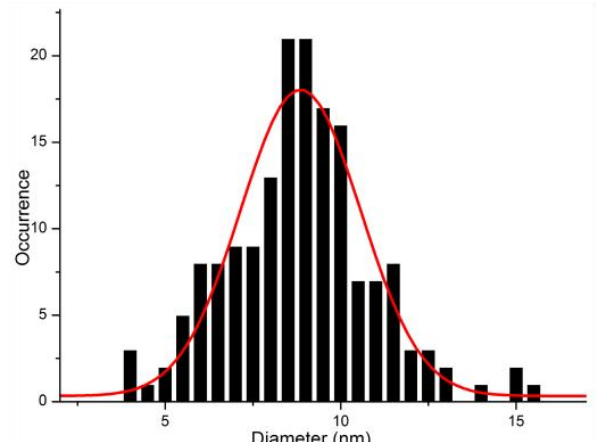

Figure S3 HRTEM image of a Zn-Cu-In-S/Zn $\mathrm{Zn}_{0.75} \mathrm{Mn}_{0.25} \mathrm{~S}$ QD (a) (scale bar: 5nm) and the corresponding FFT (b). Size distribution determined by TEM (c) 


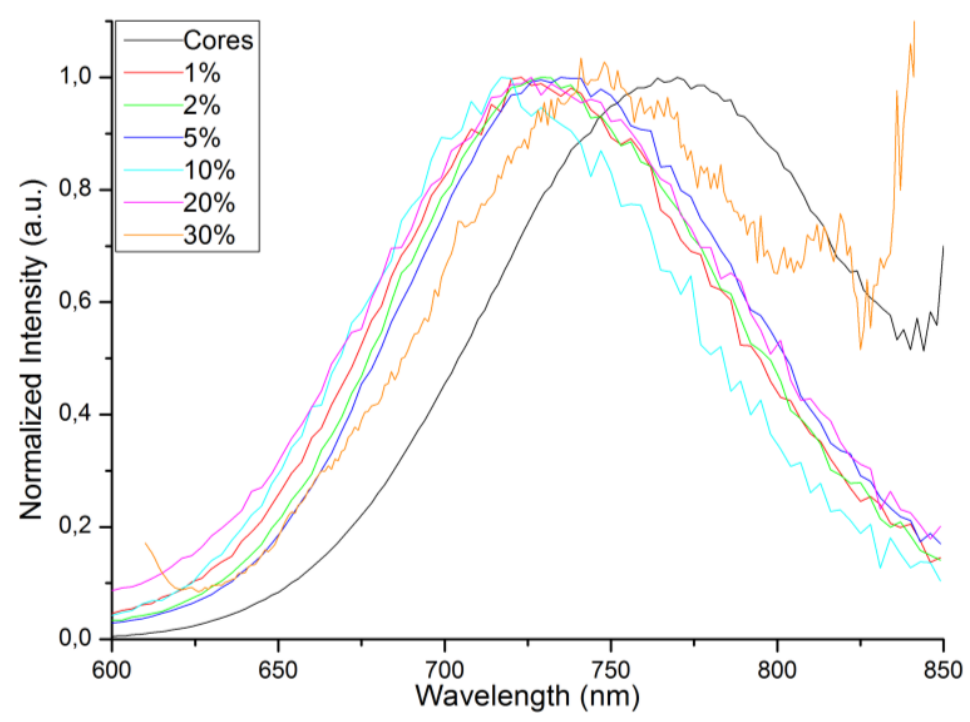

Figure S4 PL spectra of $\mathrm{Zn}-\mathrm{Cu}-\mathrm{In}-\mathrm{S} / \mathrm{Zn}_{1-\mathrm{x}} \mathrm{Mn}_{\mathrm{x}} \mathrm{S}$ QDs with various Mn content.

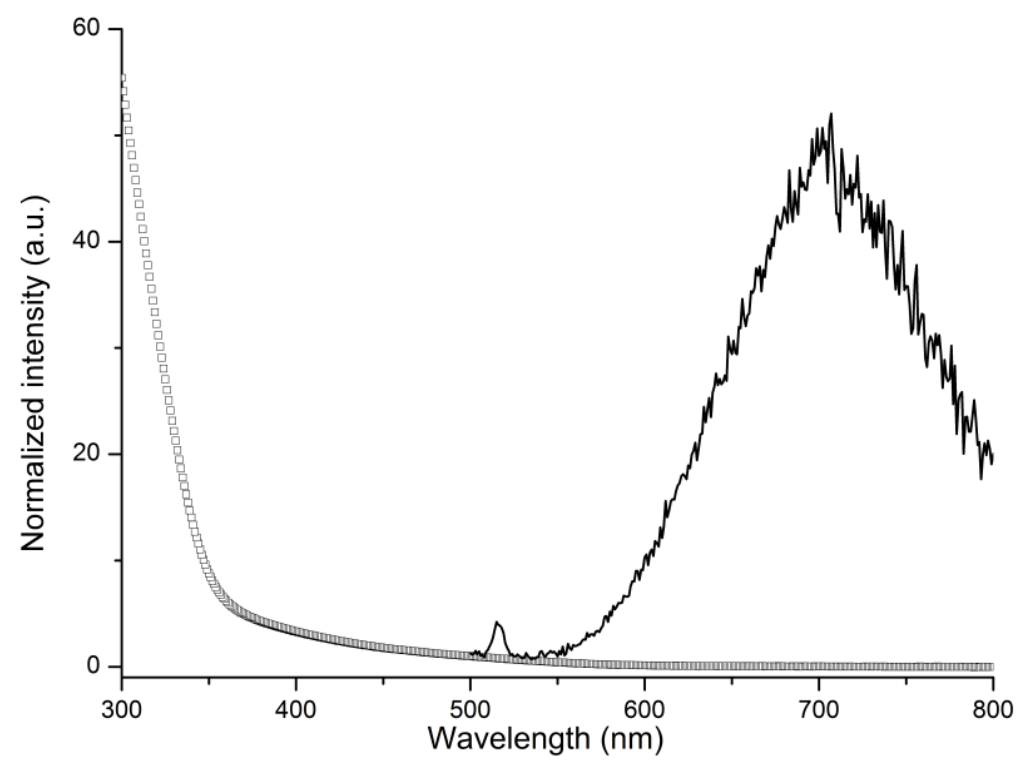

Figure S5 PL (line) and absorbance (squares) spectra of $\mathrm{Zn}-\mathrm{Cu}-\mathrm{In}-\mathrm{S} / \mathrm{Zn}_{1-\mathrm{x}} \mathrm{Mn}_{\mathrm{x}} \mathrm{S}$ QDs in water.
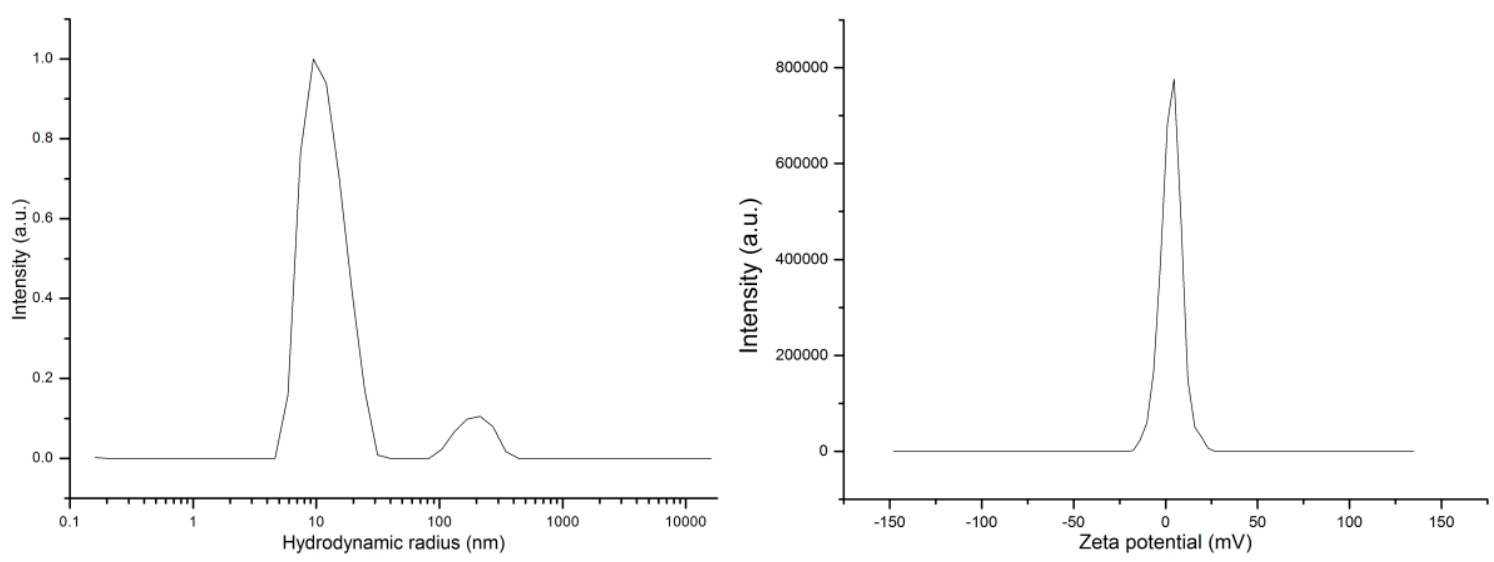

Figure S6 Left: Intensity-weighted hydrodynamic size distribution of $\mathrm{Zn}-\mathrm{Cu}-\mathrm{In}-\mathrm{Se} / \mathrm{Zn}_{0.8} \mathrm{Mn}_{0.2} \mathrm{~S}$ measured by DLS. Due to the $\mathrm{r}^{6}$ dependence of the diffusion, the population above $100 \mathrm{~nm}$ represents less than $10^{-6}$ in number. Right: Zeta potential distribution measured by laser Doppler velocimetry. 


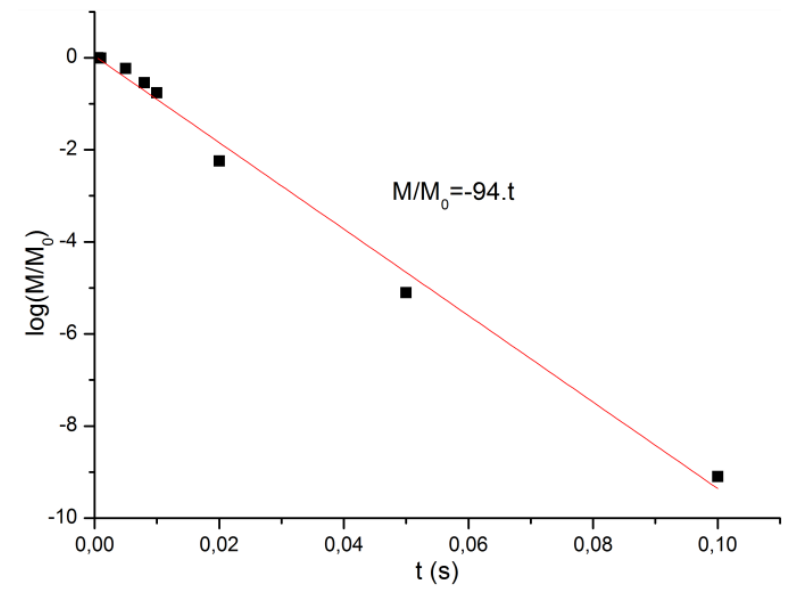

(a)

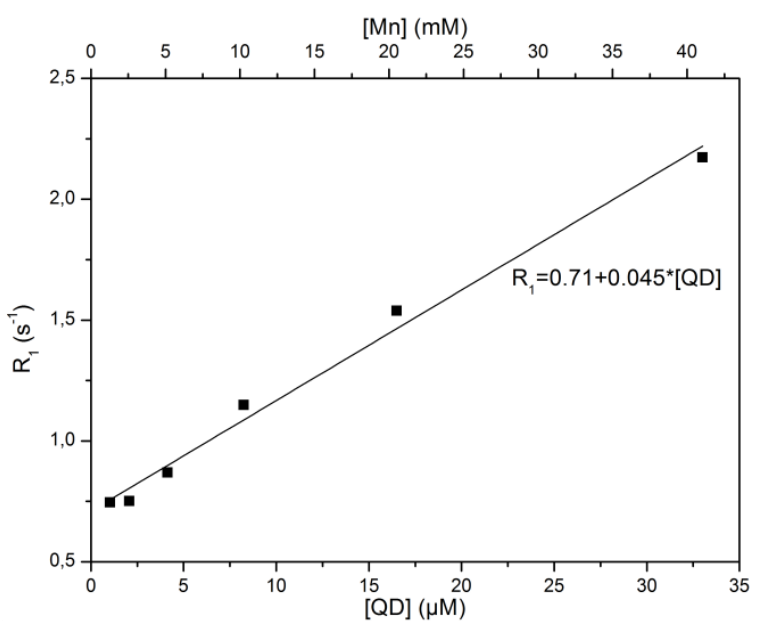

(b)

Figure S7 Characterization of the QD $\mathrm{r}_{1}$ relaxivity. (a) Normalized magnetization of water protons as a function of time between the pulses. (b) Longitudinal relaxation as a function of QD and $\mathrm{Mn}$ concentration for $\mathrm{Zn}-\mathrm{Cu}-\mathrm{In}-\mathrm{S} / \mathrm{Zn}_{0.8} \mathrm{Mn}_{0.2} \mathrm{~S}$

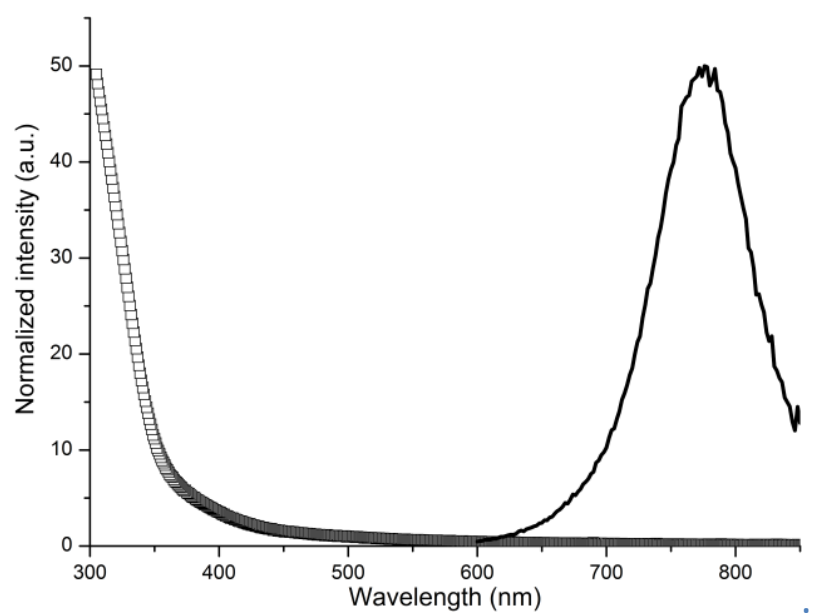

Figure S8 PL spectrum (line) and absorbance (square) spectrum of $\mathrm{Zn}-\mathrm{Cu}-\mathrm{In}-\mathrm{Se} / \mathrm{Zn}_{1-\mathrm{x}} \mathrm{Mn}_{\mathrm{x}} \mathrm{S}$ QDs in water. 


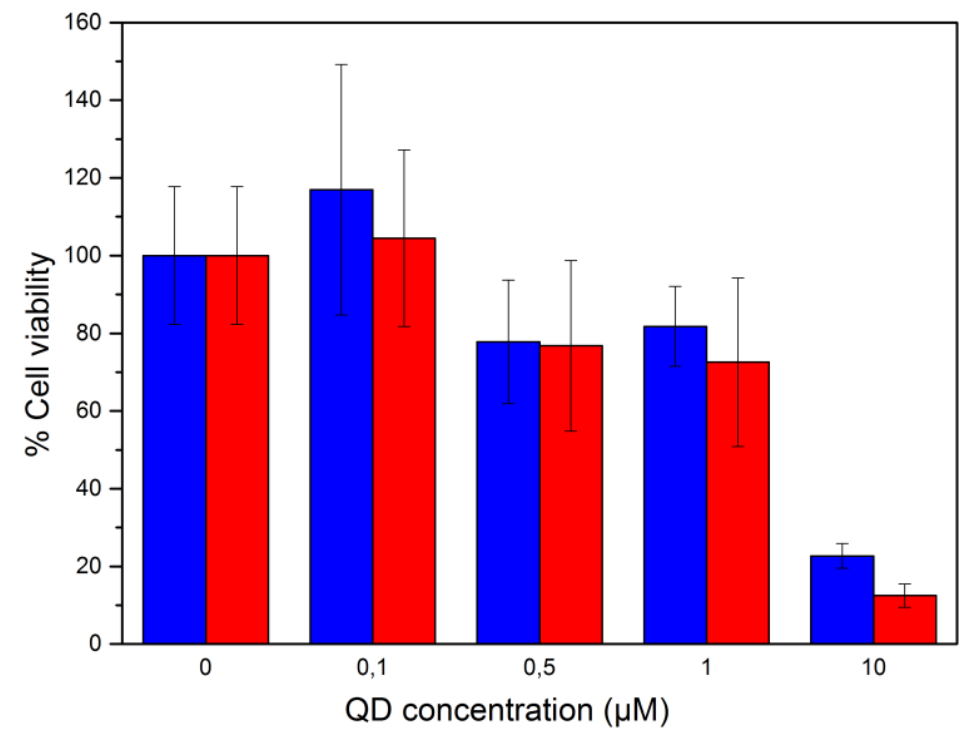

Figure S9 Cell viability of HeLa cells exposed to various QDs concentrations. In blue, results for Zn-Cu-In-Se/ZnS QDs and in red, results for $\mathrm{Zn}-\mathrm{Cu}-\mathrm{In}-\mathrm{Se} / \mathrm{Zn}_{0.8} \mathrm{Mn}_{0.2} \mathrm{~S}$

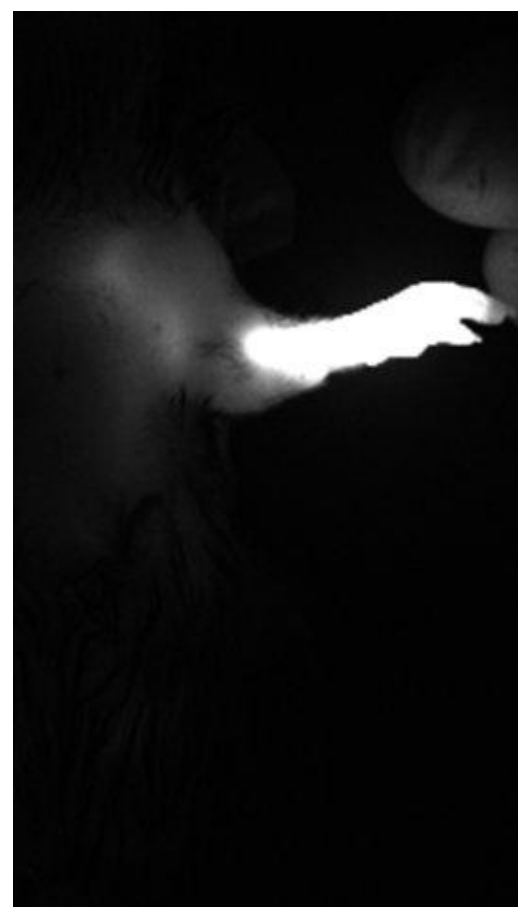

Figure S10 NIR fluorescence image of mouse after injection of a solution of $\mathrm{Zn}$-Cu-In-Se/Zn ${ }_{0.9} \mathrm{Mn}_{0.1} \mathrm{~S}$ QDs, without hiding the injection point. 